\title{
Vida Saludable: Monitoreando la presión arterial desde la casa ${ }^{1}$
} Karla P. Shelnutt ${ }^{2}$

¿Cree que su presión arterial está muy alta? ¿Ha sido diagnosticado

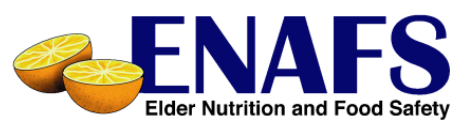
con presión arterial alta (hipertensión)? De cualquier manera, es importante que monitoree su presión arterial desde su casa al igual que en el consultorio de su médico. Esto le ayudará a su médico a determinar si usted tiene la presión arterial alta o si su plan de tratamiento está funcionando. Continue leyendo para aprender cómo monitorear la presión arterial desde la casa.

\section{Cómo Revisarla}

La Asociación Americana del Corazón recomienda el uso de un monitor automático que se coloca en la parte superior del brazo aprobado para revisar su presión arterial. Siga estas recomendaciones para asegurarse que pueda leer correctamente los resultados:

1. Asegúrese que la banda o manguito le quede bien.

2. No fume o tome bebidas con cafeína, ni haga ejercicio 30 minutos antes de medirse la presión.

3. Siéntese con su espalda derecha.

4. Ponga sus pies en posición plana en el suelo.

5. Apoye su brazo a nivel del corazón en una una mesa con superficie plana.

6. Envuelva la banda en la parte superior de su brazo.

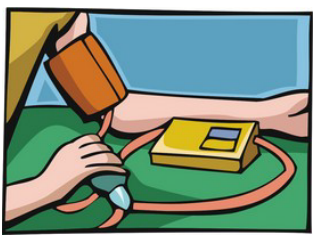

7. Tome de dos a tres resultados con un minuto de diferencia entre cada lectura y escríbalos.

8. Tome los resultados a la misma hora diariamente.

\section{¿Qué Significan los Números?}

Usted se dará cuenta que su presión arterial cambiará durante el día. Esto es normal y por eso es importante que tome siempre los resultados a la misma hora cada día. La Asociación Americana del Corazón tiene diferentes categorías de presión arterial para ayudarle a entender qué significan los números:

\begin{tabular}{|l|c|c|c|}
\hline Categoría & $\begin{array}{c}\text { Sistólica } \\
(\mathbf{m m ~ H g})\end{array}$ & $\begin{array}{c}\text { Diastólica } \\
\text { (mm Hg) }\end{array}$ \\
\hline Normal & $<120$ & $\mathrm{y}$ & $<80$ \\
\hline Prehipertensión & $120-139$ & 0 & $80-89$ \\
\hline & & & \\
\hline Alta & & & \\
\hline Etapa 1 & $140-159$ & 0 & $90-99$ \\
\hline Etapa 2 & $\geq 160$ & 0 & $\geq 100$ \\
\hline
\end{tabular}

Mantenga su registro de resultados y llévelo a cada visita médica. Esto le permitirá a su médico mantener control de su presión arterial y cambiar su plan de tratamiento de ser necesario. Use la hoja de registro de resultados en la página siguiente y haga copias a su conveniencia.

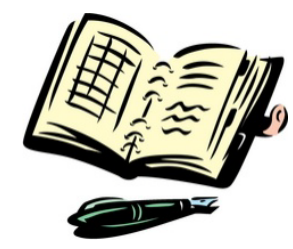

1. The English version of this Spanish document is Healthy Living: Monitoring Blood Pressure at Home (FCS8882). Este documento es FCS8882-Span, uno de una serie del Departamento de Ciencias de la Familia, la Juventud y la Comunidad, Servicio de Extensión Cooperativa de la Florida, Instituto de Alimentos y Ciencias Agrícolas, Universidad de la Florida. Publicado: Noviembre 2009. Por favor visite el sitio en la Web en EDIS http://edis.ifas.ufl.edu.

2. Karla P. Shelnutt, PhD, RD, profesora asistente, Departamento de Ciencias de la Familia, la Juventud y la Comunidad, Servicio Cooperativo de Extensión de la Florida, Instituto de Alimentos y Ciencias Agrícolas, Universidad de la Florida , Gainesville, Florida 32611. 


\section{Registro de Resultados para Presión Arterial}

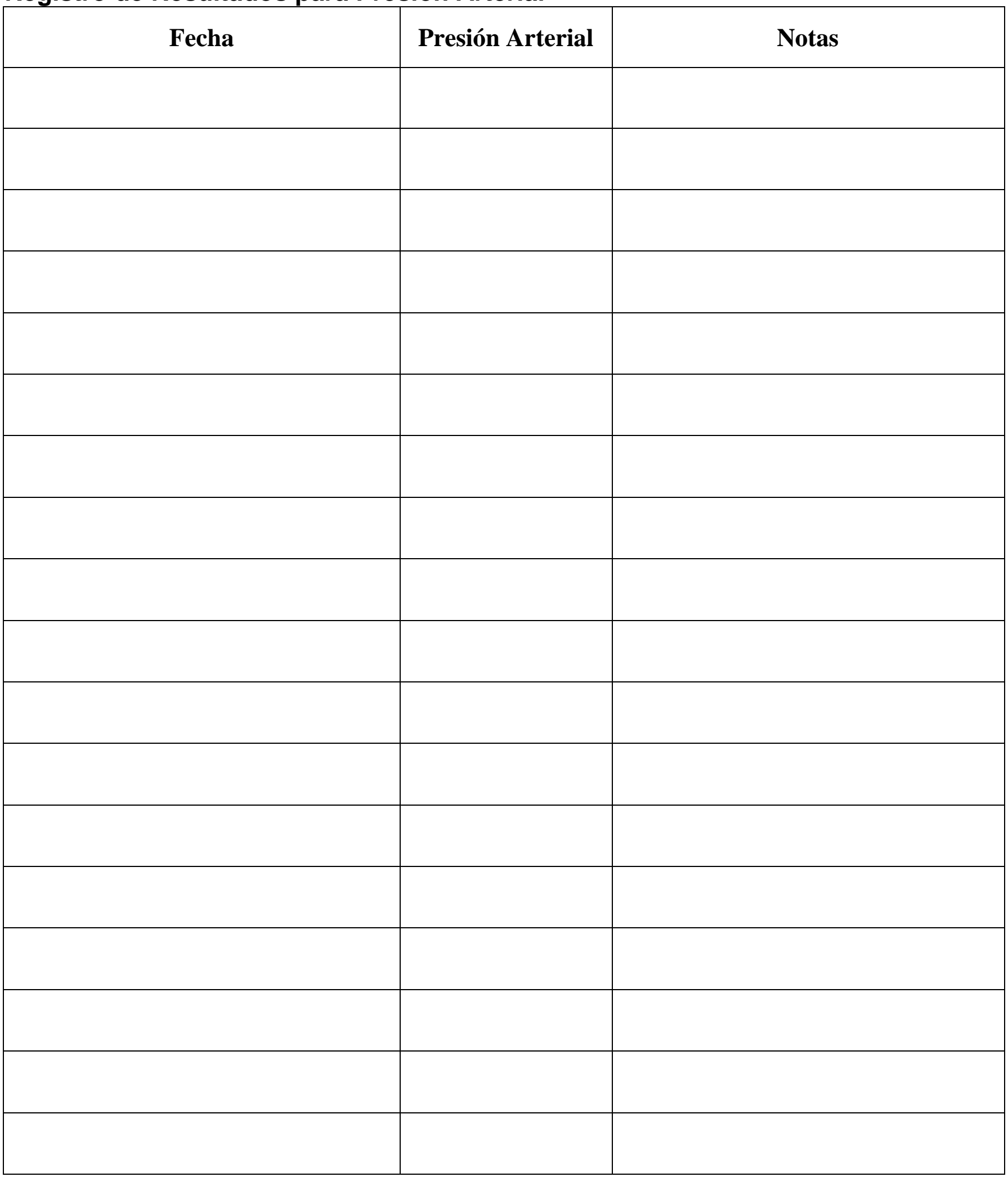

